\title{
Short-term ventilatory effects in workers exposed to fumes containing zinc oxide: comparison of forced oscillation technique with spirometry
}

\author{
H.G. Pasker*, M. Peeters*, P. Genet**†, J. Clément*, B. Nemery*, K.P. Van de Woestijne*
}

Short-term ventilatory effects in workers exposed to fumes containing zinc oxide: comparison of forced oscillation technique with spirometry. H.G. Pasker, M. Peeters, P. Genet, J. Clément, B. Nemery, K.P. Van de Woestijne. (CERS Journals Ltd 1997.

ABSTRACT: Following the occurrence of metal fume fever in some subjects after the installation of an electric furnace in a steel plant, a survey was undertaken to examine whether subjects exposed to fumes containing zinc oxide would exhibit a detectable impairment in ventilatory function, and whether a forced oscillation technique (FOT) was more suited for this detection than conventional spirometry.

Pulmonary function measurements were made in 57 exposed workers (production or maintenance) and 55 nonexposed workers (maintenance or strandcasting department) at the beginning and near the end of a work shift (day or night). Maximal expiratory volumes and flows were measured by means of a pneumotachograph, and respiratory resistance $(R \mathrm{rs})$ and reactance at various frequencies by means of a FOT. These measurements were repeated 1 day later.

During the day shift, there were no significant differences in pulmonary function between exposed and control workers. However, during the night shift, an influence of exposure on pulmonary function was revealed both by spirometry and by FOT: workers exposed at night showed a slight decrease in vital capacity (VC) and in forced expiratory volume in one second (FEV1), and a decline in respiratory resistance $(R \mathrm{rs})$ with oscillation frequency, that were more marked than in unexposed subjects. In contrast to the frequency dependence of $R \mathrm{rs}$, the changes of lung volumes and expiratory flows were related to differences in initial values between exposed and nonexposed workers. The decrease in FEV1 was maintained the day after exposure.

The forced oscillation technique proved at least as sensitive as spirometry to detect small across-shift changes in ventilatory function. Although the effects on pulmonary function were small, it is likely that they represent a subclinical response to the inhalation of small quantities of zinc oxide.

Eur Respir J 1997; 10: 1523-1529.
*Laboratorium voor Pneumologie, K.U. Leuven, Leuven, Belgium. **C.B.M.T. Usines G. Boël, La Louvière, Belgium.

\section{Correspondence: B. Nemery}

Laboratorium voor Pneumologie K.U. Leuven

Herestraat

49 B-3000 Leuven

Belgium

Keywords: Forced oscillation technique inhalation fever

metal fume fever

occupational lung disease

shift work

circadian rhythm

Received: March 191996

Accepted after revision February 31997

This study was supported by a grant from the European Coal and Steel Community.

$\doteqdot$ Dr P. Genet tragically died in a sailing accident off the Belgian coast on August 29,1996 . He will be remembered by all as a fine person and a competent and dedicated occupational physician.
To study the possible value of measuring airway impedance by means of the forced oscillation technique (FOT) in occupational medicine, we performed a field study in a factory where subjects were exposed to dusts with the potential to cause impairment of lung function. A few studies have been published in which the FOT was used in occupational medicine $[1,2]$, but, to our knowledge, there are no studies that have compared airway impedance measurements before and after exposure during work. Because the FOT has been shown to be more sensitive than spirometry in bronchial challenge tests with histamine [3], it could represent an interesting technique to detect short-term ventilatory effects caused by respiratory irritants in occupational medicine, in addition to the fact that it does not require a maximal effort from the subject.

Shortly after the installation of a new electric furnace in a steel plant in the south of Belgium, $1.5 \mathrm{yrs}$ before our study, a number of workers $(n=17)$ reported to the factory's medical service because they had experienced influenza-like symptoms (fever, chills, joint and/or muscle pains) after working near the furnace. Most also complained of respiratory symptoms (dyspnoea and/or chest tightness) $(n=13)$. Most of these cases occurred after working in the upper stories of the building where the furnace was installed. Subsequent hygiene measurements revealed high levels of dust containing zinc oxide, with dust concentrations rising with altitude. The presence of zinc was due to the fact that the steel melted in the furnace consisted of scrap originating mainly from automobiles (containing various amounts of zinc). The symptoms of the workers and the exposure circumstances fitted well with the so-called "metal fume fever", for which zinc oxide is the most frequently implicated causal agent [4]. Although most of the fumes were removed directly from the oven and from the building by an exhaust system, workers proved to be exposed to considerable amounts of fumes.

In the present study we wished to evaluate whether short-term ventilatory effects occurred in workers exposed to fumes containing zinc, by measuring lung function (lung volumes and flows by means of spirometry, and 
airway impedance by the FOT) at the beginning and at the end of one work shift and during consecutive days. A secondary objective was to compare the sensitivity of FOT with respect to spirometry.

\section{Materials and methods}

\section{Population}

The workers who were potentially exposed to the fumes were divided into two groups. The first group $(n=24)$ consisted of the production workers who were in charge of the electrical furnace. They were exposed to the fumes every working day, and spent most of the time in the control room, located close to the furnace, and on the platform where the furnace was built. The second group $(n=61)$ were the subjects who were not exposed every day, but belonged to the electrotechnical, mechanical and instrumentation services. They were involved in the maintenance of the system and performed interventions when technical failures occurred. They worked in several areas of the building, including the upper stories, where dust exposure was highest. The subjects who had previously reported to the medical service of the factory with physical complaints after working near the furnace all belonged to this group. The control group $(n=34)$ consisted of workers not exposed to the fumes produced by the electric furnace, and they worked in the continuous casting department located in a different building.

The study was approved by the plant's Committee on Safety and Hygiene.

\section{Time of measurements}

Most of the subjects investigated worked in shifts over a period of 21 days, with shift changes every 7 days. After 21 days, they had a resting period of 7 days. Some subjects worked in normal day shifts with 2 days off at the weekend.

The subjects were investigated on the first working day after rest (i.e. 7 days for the shift workers, and 2 weekend days for the day workers), and also on the second day after the work shift. At the beginning and at the end of the shift (i.e. during the first and last $2 \mathrm{~h}$, respectively) the lung function measurements (spirometry and forced oscillations) were performed. Urine samples were collected directly after the shift.

In the control group, it was only possible to measure lung function at the beginning and at the end on one single shift, this shift not necessarily being the first working day after rest. Collection of the urine sample was performed in the same way as in the exposed group.

\section{Pulmonary function measurements}

The forced oscillation data were collected with a computerized system developed by LÀndsér et al. [5]. The subject was seated and breathed quietly through a screen pneumotachograph. A pseudorandom noise pressure signal, containing all harmonics of 2-24 Hz, was applied at the mouth by means of a loudspeaker. To reduce the shunt effect of the upper airways, the subject supported his cheeks with his hands. Mouth pressure and airflow were recorded by identical differential transducers (MP45; Validyne, Northridge, CA, USA; range $\pm 0.2 \mathrm{kPa}$ ). After analogue-to-digital conversion, the signal was analysed by a Fourier transform. To eliminate the effect of breathing, the data were high-pass filtered (cut-off frequency $1 \mathrm{~Hz}$ ) and time averaged over $16 \mathrm{~s}$. Thus, the impedance of the respiratory system was calculated at intervals of $2 \mathrm{~Hz}$, from 2-24 Hz. The impedance of the respiratory system $(Z \mathrm{rs})$ was divided into a real part or resistance $(R \mathrm{rs})$, in which flow was in phase with the pressure signal, and an imaginary part or reactance $(X \mathrm{rs})$, in which flow was 90 degrees out of phase with the pressure signal. As an expression of the amount of noise on the signals of pressure and flow, a coherence function was calculated at each frequency investigated. Only the data with a coherence function between 0.95 and 1.0 were retained. At frequencies below $6 \mathrm{~Hz}$ the coherence function was often below 0.95 and, therefore, only the data obtained between 6 and $24 \mathrm{~Hz}$ were considered. The mean of three measurements was used for further evaluation, a weight factor being applied for lacking data (in one or two of the three recordings). Both for $R \mathrm{rs}$ and $X \mathrm{rs}$, the mean values between 6 and $24 \mathrm{~Hz}(R \operatorname{rs}(0) X \mathrm{rs}(0))$ and the first derivative $(R \operatorname{rs}(1), X \operatorname{rs}(1))$ of a fourth degree polynomial fitted through the data were computed [6].

Expired volumes and airflows were measured with a heated pneumotachograph (model 3813; Hans Rudolph, Wyandotte, MO, USA). Prior to each series of measurements, the system was calibrated with a $3 \mathrm{~L}$ calibration syringe. Each subject, seated and wearing a noseclip, performed two slow expirations and at least three forced expirations until the acceptability and reproducibility criteria of the American Thoracic Society (ATS) [7] were met, or until a maximum of eight forced manoeuvres was reached.

\section{Questionnaire}

The questionnaire of the European Coal and Steel Community (ECSC) for the study of respiratory symptoms [8] was completed by each subject. In addition, questions were asked about past complaints characteristic of metal fume fever (one of the following complaints during or after work: a metallic taste in the mouth; sore throat; dyspnoea; coughing; abnormal sputum production; chest pains or chest tightness; fever or chills; muscle or joint aches; abdominal pain; nausea or vomiting; dysuria; headache; blurred vision). Finally, a questionnaire was completed concerning working locations during the shift, and the development of respiratory symptoms or symptoms related to metal fume fever, on the day of the functional measurements.

\section{Exposure assessment}

Dust concentrations were measured on five different days 6 months prior to the study using stationary and personal air sampling pumps (SKC 224; Blandford, Dorset, UK; $2 \mathrm{~L} \cdot \mathrm{min}^{-1}$ ) fitted with a Casella cyclone (London, UK). Eight personal samples were taken (during 88-333 $\mathrm{min}$ ) in the working area of the production workers (control room and platform of the furnace), and 
eight static samples (during 244-307 min) at higher levels $(16-20 \mathrm{~m})$ inside the building. Gravimetric dust and metal content in respirable dust $(<5 \mu \mathrm{m})$ were determined in the same laboratory as the urine measurements. No other measurements (e.g. irritant gases) were made.

During the study, urinary zinc was measured. The urine sample was obtained directly after the shift, when the subject had taken a shower to prevent contamination of the urine by dust from the subject's body surface or clothes. The concentration of zinc was measured in the Laboratory of Industrial Toxicology and Occupational Medicine of the Université Catholique de Louvain (R. Lauwerys) using atomic absorption spectrometry. Results were expressed in $\mathrm{mg} \cdot \mathrm{L}^{-1}$, or in relation to the concentration of creatinine, determined on the same sample.

\section{Statistical analysis}

Student's t-tests were used to compare unpaired or paired samples of subject data. When more than two samples were analysed, an analysis of variance followed by Duncan's test for multiple comparisons, was used. A discriminant analysis was employed to investigate which combination of respiratory variables (differences between initial and final values combined or not with initial values) best separated the exposed subjects from the nonexposed subjects.

\section{Results}

\section{Population investigated}

The maintenance workers working in the furnace hall during the study period were grouped with the production workers, thus resulting in a group of 57 exposed subjects, and those who had not worked in the furnace hall were grouped with the control subjects, thus resulting in a group of 55 nonexposed subjects (seven maintenance workers were omitted because of incomplete data). Table 1 shows that the two groups were similar with regard to biometric data and smoking habits. In the control group, $29 \%$ of subjects had respiratory complaints, as compared to 13 and $12 \%$ in the maintenance and production workers, respectively. Seven workers (four from the control group, and three from maintenance) complained of habitual cough and sputum production; four workers (three maintenance, and one production worker) had been told by a physician that they suffered from asthma, but only one was treated for this disease. Finally, among the subjects with complaints, two subjects had a moderate decrease of forced expiratory volume in one second (FEV1). Overall, smokers and ex-smokers had lower values of the ratio $\mathrm{FEV}$ 1/vital capacity (VC) $(\mathrm{p}=0.03)$ and of
Table 1. - Biometric data, smoking habits, length of service and urinary zinc in two categories of workers

\begin{tabular}{lccc}
\hline & $\begin{array}{c}\text { Exposed } \\
\text { Workers }\end{array}$ & $\begin{array}{c}\text { Nonexposed } \\
\text { Workers }\end{array}$ & p-value* \\
\hline Subjects n & 57 & 55 & \\
Age yrs & $36 \pm 7$ & $38 \pm 6$ & 0.19 \\
Height cm & $172.8 \pm 6.7$ & $173.7 \pm 6.8$ & 0.48 \\
Weight kg & $81.1 \pm 12.9$ & $80.7 \pm 11.5$ & 0.87 \\
Smoking (NS/Ex-S/S) & $29 / 5 / 23$ & $23 / 11 / 21$ & 0.22 \\
$\quad$ Pack-yrs & $11.0 \pm 7.9$ & $14.2 \pm 7.5$ & 0.10 \\
Length of service yrs & $15.0 \pm 7.2$ & $15.3 \pm 6.5$ & 0.82 \\
Urinary zinc mg.L-1 & $0.49 \pm 0.31$ & $0.29 \pm 0.19$ & $<0.001$ \\
Zinc/creatinine & $0.33 \pm 0.16$ & $0.24 \pm 0.13$ & 0.002 \\
$\quad$ mg.g-1 creatinine & & & \\
\hline
\end{tabular}

Values are presented as mean \pm SD. NS: nonsmokers; Ex-S: exsmokers (for at least 2 yrs); S: smokers. *: unpaired Student's t-test or Chi-squared test.

maximal expiratory flow at 50\% VC (MEF50) $(\mathrm{p}=0.05)$ than nonsmokers.

\section{Influence of exposure}

The total dust concentrations, as assessed with the personal samples collected at ground floor level, ranged $1.0-22.8 \mathrm{mg} \cdot \mathrm{m}^{-3}$ (mean $( \pm \mathrm{SD}) 8 \pm 7 \mathrm{mg} \cdot \mathrm{m}^{-3}$ ) with an average of $39 \%( \pm 20 \%)$ in the alveolar (or respirable) range $(<5 \mu \mathrm{m})$. The static samplers (at high levels in the building) yielded concentrations of $8.3-71.4 \mathrm{mg} \cdot \mathrm{m}^{-3}$ (mean $\left.35 \pm 24 \mathrm{mg} \cdot \mathrm{m}^{-3}\right)$ with $87 \%( \pm 15 \%)$ of respirable dusts. The respirable dust contained traces or small amounts of nickel, chromium, lead, manganese, copper and beryllium, mostly far below the threshold limit values (TLV) [9], cadmium close to the TLV (mean $1.6 \pm 1.3 \mu \mathrm{g} \cdot \mathrm{m}^{-3}$ ) and zinc oxide (mean $5.1 \pm 4.2 \mathrm{mg} \cdot \mathrm{m}^{-3}$ ). For the latter, the concentrations of zinc oxide were below or close to the TLV (TLV time-weighted average (TWA) for fumes $\left.5 \mathrm{mg} \cdot \mathrm{m}^{-3}\right)$ at ground floor level, but exceeded that value in the upper floors $\left(7.6 \mathrm{mg} \cdot \mathrm{m}^{-3}\right.$ at a height $16-20 \mathrm{~m}$ above the oven).

Table 2. - Difference (B-A) of functional variables measured at the start $(B)$ and at the end $(A)$ of the work shift

\begin{tabular}{|c|c|c|c|c|c|}
\hline & $\begin{array}{l}\text { Exposed } \\
\text { workers }\end{array}$ & $\begin{array}{c}\text { p-value } \\
\text { paired t-test }\end{array}$ & $\begin{array}{c}\text { Nonexposed } \\
\text { workers }\end{array}$ & $\begin{array}{c}\text { p-value } \\
\text { paired t-test }\end{array}$ & $\begin{array}{c}\mathrm{p} \text {-value } \\
\text { unpaired t-test }\end{array}$ \\
\hline Subjects $\mathrm{n}$ & 57 & & 55 & & \\
\hline$\Delta \mathrm{VC} \mathrm{mL}$ & $-91 \pm 180$ & 0.0003 & $-58 \pm 199$ & 0.04 & 0.36 \\
\hline$\triangle \mathrm{FEV} 1 \mathrm{~mL}$ & $-85 \pm 183$ & 0.0009 & $-52 \pm 207$ & 0.07 & 0.37 \\
\hline$\Delta \mathrm{FEV}_{1} / \mathrm{VC} \%$ & $-0.3 \pm 3.0$ & 0.45 & $-0.1 \pm 3.5$ & 0.78 & 0.79 \\
\hline$\triangle \mathrm{PEF} \mathrm{mL} \cdot \mathrm{s}^{-1}$ & $-61 \pm 754$ & 0.55 & $+9 \pm 934$ & 0.95 & 0.67 \\
\hline$\triangle \mathrm{MEF} 75 \mathrm{~mL} \cdot \mathrm{s}^{-1}$ & $-58 \pm 706$ & 0.54 & $-185 \pm 994$ & 0.17 & 0.44 \\
\hline$\triangle \mathrm{MEF} 50 \mathrm{~mL} \cdot \mathrm{s}^{-1}$ & $-67 \pm 746$ & 0.50 & $-150 \pm 608$ & 0.07 & 0.52 \\
\hline$\Delta \mathrm{MEF} 25 \mathrm{~mL} \cdot \mathrm{s}^{-1}$ & $-62 \pm 334$ & 0.17 & $-58 \pm 364$ & 0.25 & 0.95 \\
\hline$\Delta R \operatorname{rs}(0) \quad \mathrm{hPa} \cdot \mathrm{L}^{-1} \cdot \mathrm{s}^{*}$ & $-0.062 \pm 0.319$ & 0.18 & $-0.002 \pm 0.337$ & 0.97 & 0.37 \\
\hline$\Delta R \mathrm{rs}(1) \mathrm{hPa} \cdot \mathrm{L}^{-1} \cdot \mathrm{s}^{2 *}$ & $-0.002 \pm 0.017$ & 0.53 & $+0.002 \pm 0.022$ & 0.54 & 0.39 \\
\hline$\Delta X \mathrm{rs}(0) \quad \mathrm{hPa} \cdot \mathrm{L}^{-1} \cdot \mathrm{s}^{*}$ & $-0.005 \pm 0.163$ & 0.83 & $-0.031 \pm 0.288$ & 0.45 & 0.58 \\
\hline$\Delta X \mathrm{rs}(1) \mathrm{hPa} \cdot \mathrm{L}^{-1} \cdot \mathrm{s}^{2 *}$ & $-0.004 \pm 0.017$ & 0.14 & $-0.004 \pm 0.016$ & 0.07 & 0.84 \\
\hline
\end{tabular}

Values are presented as mean \pm SD. $\Delta$ : difference; VC: vital capacity; FEV1: forced expiratory volume in one second; PEF: peak expiratory flow; MEF75, MEF50, MEF25: maximal expiratory flow at 75,50 and $25 \% \mathrm{VC}$, respectively; $R \mathrm{rs}(0), X \mathrm{rs}(0)$ : mean of total respiratory resistance and reactance, respectively; $R \mathrm{rs}(1), X_{\mathrm{rs}(1)}$ : first derivative of $R \mathrm{rs}$ and $X_{\mathrm{rs}}$ frequency function, respectively. *: excluding eight and five subjects among the exposed and nonexposed workers, respectively, because no satisfactory measurement was available at $6 \mathrm{~Hz}$, either at the beginning or at the end of the work shift. Paired t-tests compared values at the start and end of the shift, within each group. Unpaired t-tests compared the change in exposed workers with that in nonexposed workers. 
Table 2 shows that, when considered separately, only a small number of values varied significantly during work, in the exposed as well as in the nonexposed group (paired t-tests). When the two groups were compared, none of the variables appeared to be influenced differently (unpaired t-tests). A discriminant analysis combining all functional variables confirmed the lack of a significant influence of exposure $(\mathrm{p}=0.49)$. However, after exclusion of nine subjects with abnormally large changes following work shift ( $>3$ SD in either direction), the influence of exposure became significant $\left(r^{2}=0.06\right.$; $\mathrm{p}=0.02$ ) primarily because of the slope of $R$ rs (change as a function of oscillatory frequency, $R \operatorname{rs}(1)$ ), which became more negative.

Concerning the complaints elicited immediately by exposure, only throatache $(\mathrm{p}=0.025)$ and frequent coughing $(\mathrm{p}=0.09)$ were mentioned more by the exposed as compared with the nonexposed subjects. When asked about the complaints noticed frequently during or following work in the course of the past weeks or months, more frequent coughing was mentioned by the exposed workers $(p=0.11)$.

\section{Day versus night work}

In contrast to the initial values during the day shift, those measured during the night shift differed between exposed and nonexposed subjects, with VC, FEV1 and maximal expiratory flows being less among the latter (table 3). Figure 1 shows that, during the night, the maximal expiratory flow-volume curve was more concave in these workers. Also, the Rrs values showed a slight negative frequency dependence, during the night (fig. 2 ). During the day-shift, VC and FEV1 decreased slightly both in exposed and nonexposed workers (VC by $88 \pm 183 \mathrm{~mL}(\mathrm{p}=0.004)$ and $89 \pm 230 \mathrm{~mL}(\mathrm{p}=0.05)$; and FEV1 by $62 \pm 195 \mathrm{~mL}(\mathrm{p}=0.05)$ and $53 \pm 204 \mathrm{~mL}(\mathrm{p}=0.18)$ in exposed and nonexposed workers, respectively). A comparison by means of a discriminant analysis of the changes of all functional variables during the day did not reveal any statistical significance $(p=0.99)$ between exposed and nonexposed workers, even after removal of five outliers $(p=0.93)$. However, among the subjects

Table 3. - Initial functional data in exposed and nonexposed workers during the night shift

\begin{tabular}{lccc}
\hline & $\begin{array}{c}\text { Exposed } \\
\text { workers }\end{array}$ & $\begin{array}{c}\text { Nonexposed } \\
\text { workers }\end{array}$ & $\begin{array}{c}\text { p-value* } \\
\text { t-test }\end{array}$ \\
\hline Subjects n & 17 & 27 & \\
VC \% pred & $111 \pm 14$ & $99 \pm 8$ & 0.003 \\
FEV1 \% pred & $113 \pm 14$ & $96 \pm 11$ & 0.000 \\
FEV1/VC \% & $81 \pm 5$ & $78 \pm 6$ & 0.06 \\
PEF \% pred & $114 \pm 16$ & $108 \pm 24$ & 0.30 \\
MEF75 \% pred & $116 \pm 17$ & $96 \pm 29$ & 0.006 \\
MEF50 \% pred & $103 \pm 23$ & $78 \pm 22$ & 0.001 \\
MEF25 \% pred & $77 \pm 34$ & $62 \pm 24$ & 0.09 \\
$R \mathrm{rs}(0) \mathrm{hPa} \cdot \mathrm{L}^{-1} \cdot \mathrm{s}^{*}$ & $2.45 \pm 0.51$ & $2.66 \pm 0.57$ & 0.23 \\
$R \mathrm{rs}(1) \mathrm{hPa} \cdot \mathrm{L}^{-1} \cdot \mathrm{s}^{2 *}$ & $0.012 \pm 0.017$ & $-0.003 \pm 0.022$ & 0.03 \\
$X \mathrm{rs}(0) \mathrm{hPa} \cdot \mathrm{L}^{-1} \cdot \mathrm{s}^{*}$ & $0.51 \pm 0.27$ & $0.33 \pm 0.37$ & 0.11 \\
$X \mathrm{rs}(1) \mathrm{hPa} \cdot \mathrm{L}^{-1} \cdot \mathrm{s}^{2 *}$ & $0.096 \pm 0.024$ & $0.096 \pm 0.020$ & 0.98 \\
\hline
\end{tabular}

Values are presented as mean \pm SD. For abbreviations see legend to table 2. \% pred: percentage of predicted according to QUANJER et al. [10]. *: excluding three subjects because $R_{\mathrm{rs}}$ and $X$ rs values at $6 \mathrm{~Hz}$ were not acceptable, according to coherence function. studied during the night shift, the influence of exposure appeared to be highly significant (table 4), according to the discriminant analysis, primarily because of the changes in $R \operatorname{rs}(1)$ and $X \mathrm{rs}(0)\left(\mathrm{r}^{2}=0.27\right.$; $\left.\mathrm{p}=0.002\right)$. Removal of five outliers resulted in an improvement of the analysis $\left(r^{2}=0.40 ; p=0.001\right)$, the discriminant function $\mathrm{D}$ becoming:

$\mathrm{D}=+45.20 \Delta \operatorname{Rrs}(1)+0.0046 \Delta \mathrm{FEV} 1-0.0014 \Delta \mathrm{MEF} 75-0.24$

Where MEF75 is the maximal expiratory flow at $75 \%$ VC. The relative contribution of the variables is similar: $30 \%$ for $\Delta R \operatorname{rs}(1) v s 30 \%$ for $\Delta \mathrm{FEV} 1$, and $40 \%$ for $\triangle$ MEF75. Omitting the forced oscillation variables from the analysis results in a function including $\triangle \mathrm{FEV} 1$ and $\triangle$ MEF75 as significant variables $\left(\mathrm{r}^{2}=0.28 ; \mathrm{p}=0.005\right)$. Conversely, deleting indices derived from the forced expiratory manoeuvres yields a function with $\Delta R \operatorname{rs}(1)$ and $\Delta X \mathrm{rs}(0)$ with a similar $\mathrm{r}^{2}\left(\mathrm{r}^{2}=0.31 ; \mathrm{p}=0.002\right)$. In other words, during the night shift, the exposed workers differed from the unexposed by a more negative frequency dependence of $R$ rs, a larger reduction of FEV1 and, surprisingly, a smaller decrease of MEF75. The latter finding probably resulted from differences in initial values of VC and, to take this into account, the discriminant analysis was repeated by expressing the changes in percentage of the average of the initial and final values. This did not modify the results of the discriminant analysis $\left(r^{2}=0.42 ; p=0.0006\right)$, and the same variables were retained.
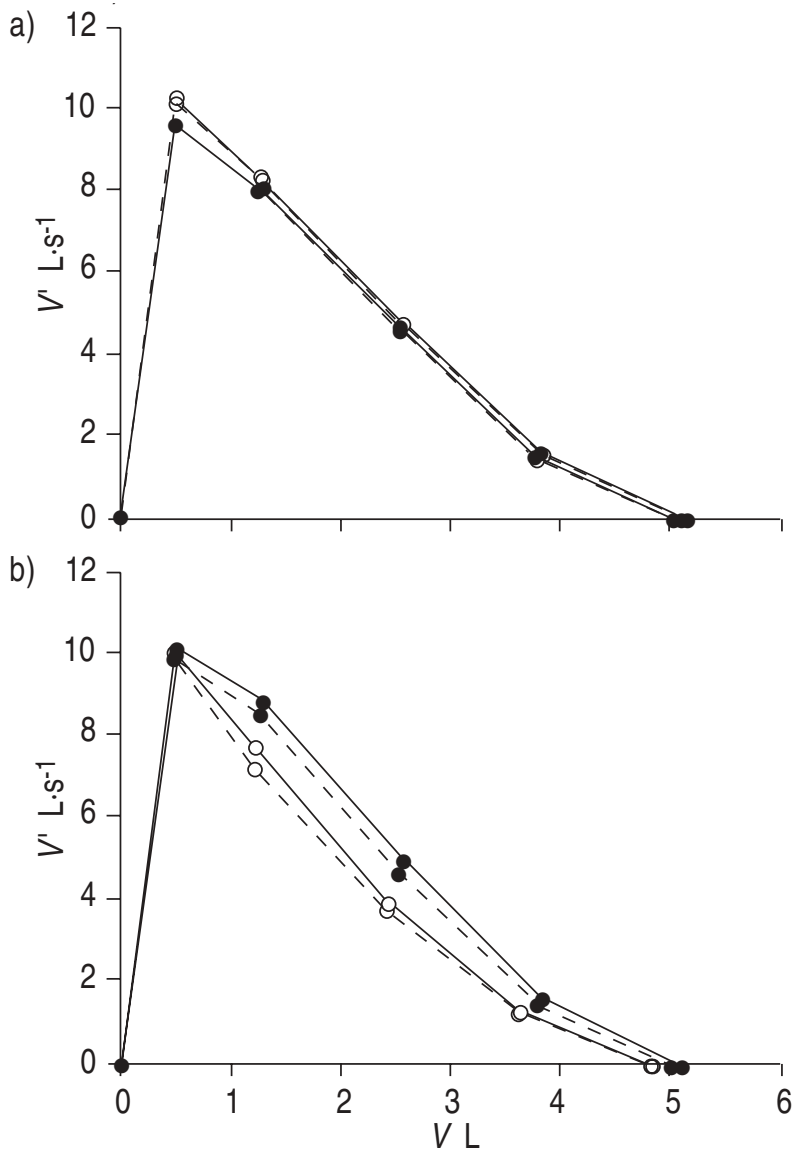

Fig. 1. - Average maximal expiratory flow-volume curves of exposed workers $(\bullet)$ and nonexposed workers $(\bigcirc)$, at the onset $(-)$ and at the end ( - - ) of the work shift. a) during the day shift; b) during the night shift. $V^{\prime}$ : flow; $V$ : volume. 

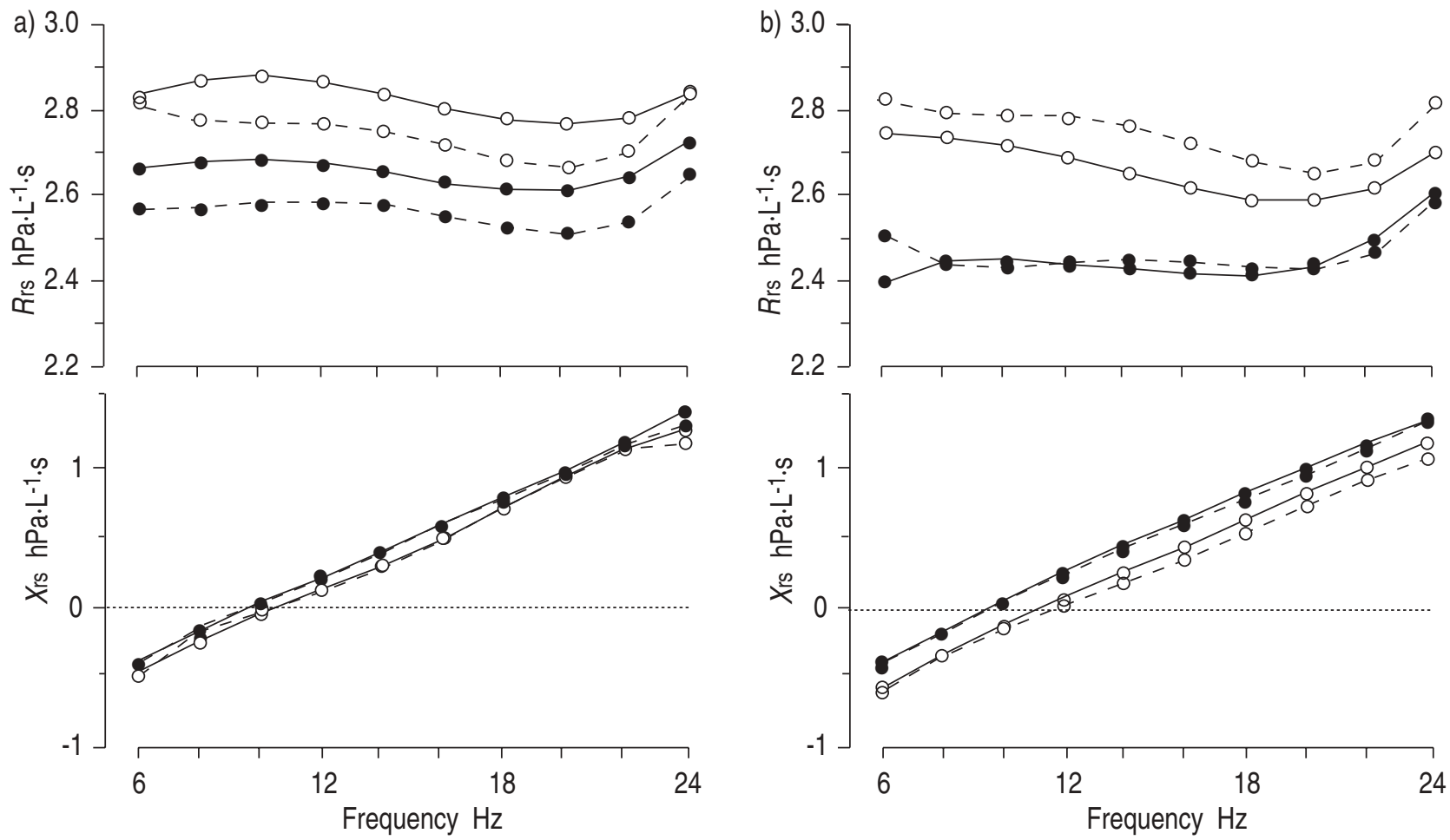

Fig. 2. - Average respiratory resistance $(R \mathrm{rs})$ and reactance $(X \mathrm{rs})$ versus oscillatory frequency curves in exposed $(\bullet)$ and nonexposed $(O)$ workers, at the onset $(-)$ and at the end (- - ) of the work shift. a) during the day shift; b) during the night shift.

\section{Day following exposure}

In the 54 production and maintenance workers in whom measurements were made the following day, only $\mathrm{VC}$ and FEV1 were still significantly lower than before exposure, whereas peak expiratory flow (PEF) was larger (not shown). When exposures during day shifts (41 subjects) and night shifts (13 subjects) were compared, the recuperation appeared to be more rapid following night work: the values of FEV1 and of maximal expiratory flows of the day after night shift were significantly similar to (or higher than) the initial values (higher for FEV1, FEV1/VC and PEF). Except for a small increase of $\operatorname{Rrs}(0)$, the impedance values were not significantly affected the day after exposure. Among

Table 4. - Difference (B-A) of functional variables measured at the onset $(B)$ and at the end $(A)$ of work during the night-shift

\begin{tabular}{|c|c|c|c|c|c|}
\hline & \multirow{2}{*}{$\begin{array}{l}\text { Exposed } \\
\text { workers }\end{array}$} & \multirow{2}{*}{$\begin{array}{c}\text { p-value } \\
\text { paired t-test }\end{array}$} & \multirow{2}{*}{$\begin{array}{c}\text { Nonexposed } \\
\text { workers }\end{array}$} & \multicolumn{2}{|c|}{ t-test $p$-value } \\
\hline & & & & paired & unpairec \\
\hline Subjects $\mathrm{n}$ & 17 & & 27 & & \\
\hline$\Delta \mathrm{VC} \mathrm{mL}$ & $-99 \pm 178$ & 0.04 & $-25 \pm 159$ & 0.42 & 0.16 \\
\hline$\triangle \mathrm{FEV}_{1} \mathrm{~mL}$ & $-140 \pm 140$ & 0.0008 & $-51 \pm 213$ & 0.22 & 0.13 \\
\hline$\triangle \mathrm{FEV}_{1} / \mathrm{VC} \quad \%$ & $-1.3 \pm 2.8$ & 0.06 & $-0.6 \pm 3.9$ & 0.45 & 0.50 \\
\hline$\triangle \mathrm{PEF} \mathrm{mL} \cdot \mathrm{s}^{-1}$ & $-299 \pm 597$ & 0.06 & $-74 \pm 965$ & 0.69 & 0.34 \\
\hline$\Delta \mathrm{MEF} 75 \mathrm{~mL} \cdot \mathrm{s}^{-1}$ & $-277 \pm 577$ & 0.06 & $-448 \pm 1008$ & 0.03 & 0.48 \\
\hline$\triangle$ MEF50 $\mathrm{mL} \cdot \mathrm{s}^{-1}$ & $-253 \pm$ & 0.11 & $-140 \pm$ & 0.19 & 0.52 \\
\hline$\Delta \mathrm{MEF} 25 \mathrm{~mL} \cdot \mathrm{s}^{-1}$ & $-105 \pm 389$ & 0.28 & $-9 \pm 341$ & 0.90 & 0.39 \\
\hline$\Delta R \mathrm{rs}(0) \quad \mathrm{hPa} \cdot \mathrm{L}^{-1} \cdot \mathrm{s}^{*}$ & $+0.005 \pm 0.313$ & 0.95 & $+0.084 \pm 0.351$ & 0.24 & 0.47 \\
\hline$\Delta R \operatorname{rs}(1) \quad \mathrm{hPa} \cdot \mathrm{L}^{-1} \cdot \mathrm{s}^{2 *}$ & $-0.007 \pm 0.011$ & 0.02 & $+0.002 \pm 0.024$ & 0.63 & 0.09 \\
\hline$\Delta X \mathrm{rs}(0) \quad \mathrm{hPa} \cdot \mathrm{L}^{-1} \cdot \mathrm{s}^{*}$ & $-0.025 \pm 0.121$ & 0.42 & $-0.064 \pm 0.316$ & 0.32 & 0.58 \\
\hline$\Delta X \mathrm{rs}(1) \mathrm{hPa} \cdot \mathrm{L}^{-1} \cdot \mathrm{s}^{2 *}$ & $-0.001 \pm 0.010$ & 0.74 & $-0.004 \pm 0.017$ & 0.25 & 0.46 \\
\hline
\end{tabular}

For abbreviations see legend to table $2 . *$ : excluding three subjects among the exposed because $R \mathrm{rs}$ and $X \mathrm{rs}$ values at $6 \mathrm{~Hz}$ were not acceptable, according to coherence function. Paired t-tests compared values at the start and end of the shift, within each group. Unpaired t-tests compared the change in exposed workers with that in nonexposed workers. the 13 nonexposed subjects studied three times, i.e. at the onset and after work, and 1 day later, only $\mathrm{VC} \mathrm{dec-}$ reased significantly following work. The recovery of $\mathrm{VC}$ was not complete the day after.

\section{Discussion}

The purpose of the present study was: 1) to investigate whether exposure to fumes containing zinc oxide exerts acute deleterious effects on pulmonary function, and whether this effect is immediate or delayed; and 2) to compare the sensitivities of the FOT and spirometry.

Ideally, the pulmonary function data of the exposed workers should have been compared to those obtained on an exposure-free day. However, this was not feasible and we, therefore, chose the second best option consisting of comparing the observed changes with similar data obtained in a comparable control population. Three populations of workers were available for this study: production workers exposed continuously to (low levels of) the fumes; maintenance workers exposed only intermittently, but probably to higher con centrations of dust; and an unexposed control group. These unexposed subjects came from a continuous casting department and were, therefore, not entirely free from exposure to dust. However, they had no known exposure to fumes containing 
zinc and the levels of dust containing iron were much lower, thanks to engineering controls.

The three groups were not exactly comparable in terms of age, smoking habits and pulmonary function data: production workers tended to be younger; maintenance workers smoked less and demonstrated, probably as a consequence of the smaller amount of smoking, better values of $\mathrm{VC}$ and FEV1 (expressed as a percentage of expected values). Overall, these differences were small, however. Among the maintenance workers, about half proved to have been exposed to the fumes during at least one work shift during the period of study. The latter were added to the production workers to investigate the effect of exposure. That exposure results in a larger inhalation of zinc oxide fumes was confirmed by the amount of zinc excreted in the urine, which was significantly higher in the exposed workers, although these changes were small. Few or no data are available regarding the biological monitoring of zinc-exposed workers [11].

The effect of exposure appears to differ depending on whether it occurred during the day or at night. During the day shift, small decreases in VC and in FEV1 were observed in most workers. These decreases were not significantly different between exposed and nonexposed people. However, at night, exposed workers demonstrated significant decreases in VC, FEV1 and slope of $R$ rs (more negative frequency dependence of $R \mathrm{rs}$ ), and decreases in FEV1/VC, in PEF and in MEF75 at the limit of statistical significance. This contrasts with a more marked isolated decrease in MEF75 in nonexposed workers. The mechanisms for this apparent higher sensitivity to occupational dust exposure during the night are still unclear, but our observation is in keeping with a previous study by NEMERY and co-workers [12], in which steelworkers from a strandcasting department exposed to high levels of dust (without zinc oxide) demonstrated an exposure-related decrease in FEV1 and forced expiratory flow over the middle half of the vital capacity (FEF25-75) only during the night shift. Maximal expiratory volumes and flows demonstrate a circadian rhythm, characterized by a decrease of all values at night [13]. However, the night shift is not associated systematically with larger decrements of pulmonary function [14]. In a study performed on more than 1,000 unexposed bluecollar workers, GHIO et al. [15] were not able to provide evidence for a different influence of day or evening shifts either on FEV1 or PEF. Exposure to high levels of dust, thus, appears to magnify the effect of circadian variation, possibly because of an increase in the basal tone and, thus, a narrowing of the airways, or because of an increased bronchial reactivity during the night. If so, the circadian variability might unmask an effect of dust that remains subliminal during the day. Further experimental research in this area seems warranted.

When the changes occurring at night in exposed and unexposed workers were compared by means of a discriminant analysis, the effect of exposure was best described by a combination of a larger decrease in FEV1, a negative frequency dependence of $R$ rs and a smaller decrease in MEF75. Because the latter finding is paradoxical, we wondered whether the more pronounced decrease in MEF75 in unexposed workers was the result of the difference in initial values of volumes and maximal flows, which proved to be smaller in the unexposed workers. The difference in initial values may be related to differences in smoking habits among the night workers: there were more smokers and ex-smokers in nonexposed than in exposed workers (59 vs 47\%). Indeed, ENARSON and YEUNG [16] documented a direct relationship between initial value and change in FEV1 over the work shift in minimally exposed nonsmokers.

As a check for the importance of the initial values, we introduced, in addition to the changes, the initial values of spirometric and forced oscillation parameters into the discriminant analysis: three variables were retained as contributing significantly to the separation between exposed and nonexposed night workers: the initial values of PEF (\% pred) and FEV1 (\% pred), and change of $R \operatorname{rs}(1)$. This new function explains up to $60 \%$ of the variance between both groups $(\mathrm{p}<0.0001)$, i.e. twice the variance explained by the changes of functional parameters. This means that the difference in initial values between exposed and nonexposed workers may, indeed, explain the changes occurring during the night shift, at least as far as volumes and maximal expiratory flows are concerned. This is not the case for $R$ rs: the more negative frequency dependence of $R$ rs, observed following exposure, is independent of the initial values of $R$ rs. This suggests that the FOT is at least as sensitive as spirometry to detect small across-shift changes in ventilatory function. Since the former technique has the advantage of requiring only $16 \mathrm{~s}$ per measurement with a minimal co-operation from the subject, it seems to be of particular interest for the study of changes of airway impedance in occupational medicine. The apparatus is commercially available and can be set up close to the exposed workers. However, some protection of the equipment against dust should be provided to avoid clogging of the pneumotachograph.

How long does the effect of exposure persist? Although the data available were more limited, the study of the functional indices the day after the work shift suggests that the decrease in FEV1 was maintained the day after exposure. It is, therefore, possible that the influence of the dust is not reversed rapidly after the cessation of exposure.

The effects of zinc fume fever on pulmonary function are classically considered to be trivial, but there are indications, even in the older literature, that this is not always so [17]. It is a classical feature of occupational field research that a survey is initiated after the implementation of preventive measures to avoid continued exposure to a recognized hazard, and this explains why no subject reported the typical symptoms of metal fume fever at the time of the present study. Nevertheless, small but consistent effects on pulmonary function were found, and it is likely that they represent a subclinical response to the inhalation of low quantities of zinc oxide. The long-term significance of such findings is not established, but there has recently been considerable interest in the possible relationship between acute, i.e. acrossshift, ventilatory changes and chronic airways obstruction. At least with organic dusts, such as cotton or grain, the occurrence of acute ventilatory effects has been shown to reflect the potential for long-term decline in lung function [18]. We do not know whether this is also true for metallic dusts, such as zinc oxide. Although the 
epidemiological evidence regarding the long-term effects of metal fume fever is still very limited [19], it seems that the prevalence of chronic obstructive lung disease is higher in subjects, such as welders, who have had episodes of metal fume fever [20].

In conclusion, in a group of steelworkers exposed to moderate levels of zinc oxide fumes, we found small but significant across-shift effects on ventilatory function, as assessed by conventional spirometry and the forced oscillation technique. For reasons that are unclear, but consistent with previous findings, the changes were noticeable only across the night shift. Even if the small effects observed were in themselves of no clinical significance, they could, by analogy with what has been shown with other agents, be indicative of a risk of longterm adverse effects on ventilatory function.

Acknowledgements: The authors thank the management, unions and participating workers of the Usines G. Boël for their extremely good collaboration. They thank R. Schepers for her excellent work in carrying out the data analysis.

\section{References}

1. Jorna THJM, Borm PJA, Wesseling G, Wouters EFM. Application of the forced oscillation technique (FOT) in different occupational settings. Eur Respir Rev 1994; 4: $155-158$

2. Pairon JC, Iwatsubo Y, Hubert C, et al. Measurement of bronchial responsiveness by forced oscillation technique in occupational epidemiology. Eur Respir J 1994; 7: 484-489.

3. Van Noord JA, Clément J, Van de Woestijne KP, Demedts $\mathrm{M}$. Total respiratory resistance and reactance as a measurement of response to bronchial challenge with histamine. Am Rev Respir Dis 1989; 139: 921-926.

4. Gordon T, Fine JM. Metal fume fever. Occup Med 1993; 8: $505-517$.

5. Làndsér FJ, Nagels J, Demedts M, Billiet L, Van de Woestijne KP. A new method to determine frequency characteristics of the respiratory system. J Appl Physiol 1976; 41: 101-106.

6. Làndsér FJ, Clément J, Van de Woestijne KP. Normal values of total respiratory resistance and reactance determined by forced oscillations: influence of smoking. Chest 1982; 81: 586-591.
7. American Thoracic Society. Standardisation of spirometry: 1987 Update. Am Rev Respir Dis 1987; 136: 1285-1297.

8. Minette A. Questionnaire of the European Coal and Steel Community (ECSC) on respiratory symptoms: 1987 updating of the 1962 and 1967 questionnaires for studying chronic bronchitis and emphysema. Eur Respir $J$ 1989; 2: 165-177.

9. American Conference of Governmental Industrial Hygienists (ACGIH), 1994-1995. Threshold Limit Values for Chemical Substances and Physical Agents and Biological Exposure Indices. Cincinnati, Ohio, ACGIH, 1994.

10. Quanjer PhH, Tammeling GJ, Cotes JE, Pedersen OF, Peslin R, Yernault J-C. Lung volumes and forced ventilatory flows. Report Working Party "Standardization of Lung Function Tests". European Coal and Steel Community. Eur Respir J 1993; 6 (Suppl. 16): 5-40.

11. Lauwerys R. Occupational toxicology. In: Amdur MO, Doull J, Klaassen CD, eds. Casarett and Doull's Toxicology. The Basic Science of Poisons. New York, Pergamon, 1991, pp. 947-969.

12. Nemery B, Van Leemputten R, Goemaere E, Veriter C, Brasseur L. Lung function measurements over 21 days shiftwork in steelworkers from a strandcasting department. Br J Ind Med 1985; 42: 601-611.

13. Hetzel MR. The pulmonary clock. Thorax 1981; 36: 481-486.

14. Guberan E, Williams MK, Walford J, Smith MM. Circadian variation of FEV in shift workers. $\mathrm{Br} J$ Ind Med 1969; 26: 121-125.

15. Ghio AJ, Castellan RM, Kinsley KB, Hankinson JL. Changes in forced expiratory volume in one second and peak expiratory flow rate across a work-shift among unexposed blue collar workers. Am Rev Respir Dis 1991; 143: $1231-1234$

16. Enarson DA, Yeung M. Determinants of changes in FEV1 over a workshift. Br J Ind Med 1985; 42: 202-204.

17. Nemery B, Demedts M. Respiratory involvement in metal fume fever. Eur Respir J 1991; 4: 764-765.

18. Becklake MR. Relationship of acute obstructive airway change to chronic (fixed) obstruction. Thorax 1995; 50 (Suppl. 1): S16-S21.

19. Nemery B. Metal toxicity in the respiratory tract. Eur Respir J 1990; 3: 202-219.

20. Cotes JE, Feinmann EL, Male VJ, Rennie FS, Wickham CAC. Respiratory symptoms and impairment in shipyard welders and caulker/burners. Br J Ind Med 1989; 46: 292-301. 